\title{
The unusual redox properties of fluoroferrocenes revealed through a comprehensive study of the haloferrocenes
}

\author{
Michael S. Inkpen ${ }^{\mathrm{a} \dagger}$, Shuoren $\mathrm{Du}^{\mathrm{a}, \mathrm{b} \dagger}$ Mariana Hildebrand ${ }^{\mathrm{a}}$, Andrew J. P. White ${ }^{\mathrm{a}}$, Nicholas M. Harrison ${ }^{\mathrm{a}}$, \\ Tim Albrecht ${ }^{\mathrm{a} *}$ and Nicholas J. Long ${ }^{\mathrm{a} *}$ \\ ${ }^{a}$ Department of Chemistry, Imperial College London, London, SW7 2AZ, UK \\ ${ }^{\mathrm{b}}$ College of Chemistry and Molecular Engineering, Peking University, Beijing, 100871, China \\ Supporting Information Placeholder
}

\begin{abstract}
We report the synthesis and full characterization of the entire haloferrocene $(\mathrm{FcX})$ and $1,1^{\prime}$ '-dihaloferrocene (fc $\left.\mathrm{X}_{2}\right)$ series $(\mathrm{X}=\mathrm{I}, \mathrm{Br}, \mathrm{Cl}, \mathrm{F} ; \mathrm{Fc}=$ ferrocenyl, fc = ferrocene-1,1'-diyl). Finalization of this simple, yet intriguing set of compounds has been delayed by synthetic challenges associated with the incorporation of fluorine substituents. Successful preparation of fluoroferrocene $(\mathbf{F c F})$ and 1,1'-difluoroferrocene $\left(\mathbf{f c F}_{2}\right)$ were ultimately achieved using reactions between the appropriate lithiated ferrocene species and $N$-fluorobenzenesulfonimide (NFSI). The crude reaction products, in addition to those resulting from analogous preparations of chloroferrocene $(\mathbf{F c C l})$ and 1,1'-dichloroferrocene $\left(\mathbf{f c C l} \mathbf{C l}_{\mathbf{2}}\right)$, were utilized as model systems to probe the limits of a previously reported 'oxidative purification' methodology. From this investigation and careful solution voltammetry studies, we find that the fluorinated derivatives exhibit the lowest redox potentials of each of the $\mathrm{FcX}$ and $\mathrm{fcX} \mathrm{X}_{2}$ series. This counter-intuitive result is discussed with reference to the spectroscopic, structural and first principles calculations of these and related materials.
\end{abstract}

\section{INTRODUCTION}

The first synthetic routes to haloferrocenes (fcX) and 1,1'dihaloferrocenes $\left(\mathrm{fcX} \mathrm{X}_{2}\right)$ were reported only 4 years after the discovery of ferrocene itself $(\mathrm{X}=\mathrm{I}, \mathrm{Br}, \mathrm{Cl}, \mathrm{F}$; fc $=$ ferrocene1,1 '-diyl, Fc $=$ ferrocenyl). ${ }^{1}$ In the subsequent 60 years, these precursors have been reacted on to form a wide variety of useful materials including redox-active ligands, ${ }^{2}$ polymers, ${ }^{3}$ or model systems for the study of charge transfer. ${ }^{4}$ In the published literature, a remarkable omission from this series is 1,1'-difluoroferrocene $\left(\mathbf{f c F}_{\mathbf{2}}\right)$ - though we note several preparative attempts have been described. ${ }^{5}$ Furthermore, until very recently ${ }^{6}$ the only known methods to synthesize fluoroferrocene (FCF) utilized explosive perchloryl fluoride ${ }^{1 \mathrm{~d}, 7}$ or toxic mercurated materials. ${ }^{8}$ Perhaps as a result, to the best of our knowledge only three other ferrocenes comprising a $\mathrm{Cp}-\mathrm{F}$ bond are known: 2-fluoro[(dimethylamino)methyl]ferrocene, ${ }^{\text {a }}$ 1-fluoro-2-(2-pyridyl)ferrocene ${ }^{9}$ and 1,2,3,4,5pentafluoroferrocene. ${ }^{6}$ To date, there are more known examples of fluorinated ruthenocenes $\left(\sim 11\right.$ complexes $\left.^{10}\right)$ and no reports of fluorinated osmocenes. Despite significant interest, it has not yet proved possible to synthesize any perfluorometallocenes. ${ }^{11}$ In this work, we corroborate a safer approach for the preparation of $\mathbf{F c F}$, and communicate a synthetic route to $\mathbf{f c F}_{2}$ (Scheme 1).

\section{(I) Synthesis}

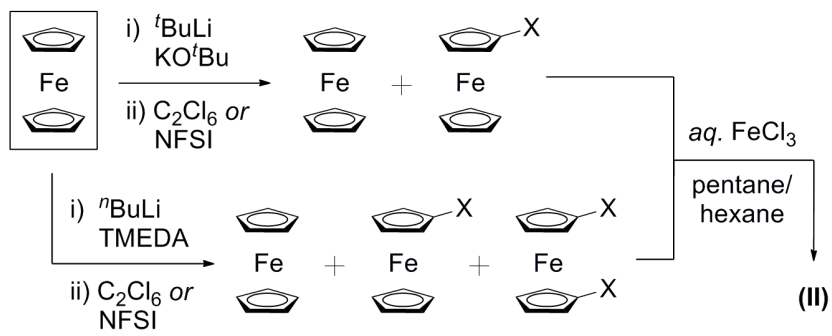

(II) Oxidative purification

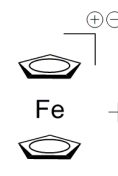

(water)

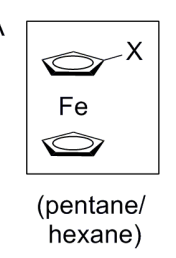

hexane)

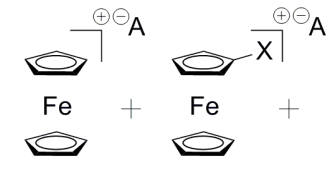

(water)

(water)

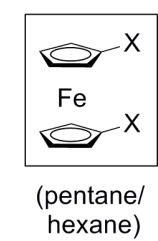

Scheme 1. Synthesis and oxidative purification of FcCl and $\mathbf{F c F}$ (top/left), and $\mathbf{f} \mathbf{c} \mathbf{C l}_{\mathbf{2}}$ and $\mathbf{f} \mathbf{c} \mathbf{F}_{\mathbf{2}}$ (bottom/right) (NFSI $=\mathrm{N}$ fluorobenzenesulfonimide; $\mathrm{X}=\mathrm{Cl}, \mathrm{F} ; \mathrm{A}^{-}=\mathrm{Cl}^{-}$, aq. $\left[\mathrm{FeCl}_{3}\right]^{-}$or aq. $\left.\left[\mathrm{FeCl}_{4}\right]^{-}\right) .{ }^{12}$

Historically, investigations into chlorinated and fluorinated metallocenes have been motivated by their potential applications as polymeric/structural materials with combined thermal, radiation and oxidation-resistance. ${ }^{11 \mathrm{a}, 13}$ Our initial interest lay in the use of these materials as models to explore the limits of a previously reported 'oxidative purification' technique. ${ }^{14}$ The latter can be used to separate redox-active mixtures of similar polarity which are typically difficult to purify using conven- 
tional techniques (for example, chromatography or recrystallization). By washing $n$-alkane solutions comprising $\mathrm{FcH}$ and $\mathrm{FcX}$ (or $\mathrm{FcH}, \mathrm{FcX}$ and $\mathrm{fcX}$ ) with aqueous solutions of $\mathrm{FeCl}_{3}$ made up to appropriate concentrations, components of each mixture can be oxidized sequentially. We, ${ }^{14 \mathrm{c}}$ and others, ${ }^{14 \mathrm{~b}}$ have observed that the resulting $[\mathrm{FcH}]^{+} \mathrm{A}^{-}$(or $[\mathrm{FcH}]^{+} \mathrm{A}^{-}$and $\left.[\mathrm{FcX}]^{+} \mathrm{A}^{-}\right)$species are water-soluble and easily extracted $(\mathrm{X}=$ $\mathrm{I}, \mathrm{Br} ; \mathrm{A}^{-}=\mathrm{Cl}^{-}$, aq. $\left[\mathrm{FeCl}_{3}\right]^{-}$or aq. $\left.\left[\mathrm{FeCl}_{4}\right]^{-}\right),{ }^{12}$ leaving only the complex with the highest redox potential dissolved in the organic phase. This methodology is conceptually similar to pioneering work of Cunningham and McMillin. ${ }^{14 a}$ Given the success of this approach, it was of interest to determine the maximum equilibrium potential that can be utilized with the biphasic aqueous $\mathrm{FeCl}_{3} / n$-alkane system. This is however not trivial as reactions are likely occurring at the solution-solution interface. We considered that an approximate limit might be deduced by extending the purification approach to the entire $\mathrm{FcX}$ and $\mathrm{fcX}_{2}$ series (providing a range of equilibrium potentials for testing). Given the high electronegativity of fluorine, it was hypothesized that $\mathbf{f c F}_{\mathbf{2}}$ would be the most difficult to oxidize of all. Remarkably, we instead found $\mathbf{F c F}$ and $\mathbf{f} \mathbf{c F} \mathbf{F}_{\mathbf{2}}$ to be the easiest to oxidize of the $\mathrm{FcX}$ and $\mathrm{fcX}_{2}$ series. This unexpected result and its implications are discussed with reference to the experimental, structural and first principle calculations of these and related materials. (We note that during the preparation of this manuscript, a related study was published which corroborates our findings. ${ }^{15}$ )

\section{RESULTS AND DISCUSSION}

\section{(a) Synthesis and 'oxidative purification'}

The synthesis of most monohalo- and 1,1'-dihaloferrocenes is readily achieved using well-established selective preparations of monolithioferrocene ( $\mathrm{FcLi}$, using ${ }^{t} \mathrm{BuLi}$ and $\left.{ }^{t} \mathrm{BuOK}\right),{ }^{16}$ and the 1,1'-dilithioferrocene- $N, N, N^{\prime}, N^{\prime}$-tetramethylethane-1,2diamine adduct (fcLi $i_{2}$ TMEDA, using ${ }^{n} \mathrm{BuLi}$ and TMEDA). ${ }^{17}$ These reactive precursors may subsequently be halogenated through combination with an appropriate (electrophilic) halide source. It should be noted that the above conditions favoring monolithiation can still provide 1,1'-dilithioferrocene in small to moderate quantities (as evidenced by the occasional observation of 1,1'-disubstitued products after quenching). In line with previous discussions, ${ }^{16}$ we suggest dilithiation can be minimized by: (a) slow addition of ${ }^{t} \mathrm{BuLi}$ and (b) efficient stirring of the reaction mixture (both serving to reduce local heating and to avoid high local concentrations).

$\mathbf{F C C l}^{18}$ and $\mathbf{f} \mathbf{C C l}_{2}{ }^{5 \mathrm{a}}$ were accordingly prepared by the reaction of hexachloroethane at $-78^{\circ} \mathrm{C}$ with $\mathrm{FcLi}$ or $\mathrm{fcLi} \mathrm{Li}_{2}-\mathrm{TMEDA}$, respectively (Scheme 1). Subsequent extraction of the crude reaction material with $n$-hexane provided mixtures of $\mathrm{FcH}$ and $\mathbf{F c C l}$, or FcH, $\mathbf{F c C l}$, and $\mathbf{f c C l} \mathbf{l}_{2}$. These extracts were repeatedly agitated with aqueous solutions of $\mathrm{FeCl}_{3}$ (varying their concentration, the number of washings and the volume of oxidant solution as described in Table 1). Lower concentrations of $\mathrm{FeCl}_{3}$ have previously been found to reduce the 'oxidizing power' of the aqueous phase (and vice versa), in accordance with the Nernst equation. ${ }^{14 \mathrm{c}}$ Whereas $0.2 \mathrm{M} \mathrm{FeCl}_{3}$ is sufficient to efficiently oxidize $\mathrm{FcH}\left(E_{1 / 2}=0.00 \mathrm{~V} v s . \mathrm{FcH} / \mathrm{FcH}^{+}\right), 3.0 \mathrm{M}$ $\mathrm{FeCl}_{3}$ was required to efficiently oxidize $\mathbf{F c C l}\left(E_{1 / 2}=0.16 \mathrm{~V}\right.$ vs. $\left.\mathrm{FcH} / \mathrm{FcH}^{+}\right)$. (We stress that use of an inappropriate [excessive] volume or concentration of aqueous $\mathrm{FeCl}_{3}$ for washing can readily oxidize the entire sample.) With this approach, pure $\mathbf{F c C l}$ and $\mathbf{f} \mathbf{C C l}_{2}$ (free of other ferrocene-based species) were ultimately obtained following filtration of the treated solution through a pad of silica.

Table 1. Experimental details for the oxidative purification of different haloferrocene mixtures $(\mathrm{FcH}$ and $\mathrm{FcX}$ or $\mathrm{FcH}, \mathrm{FcX}$ and $\mathrm{fc} \mathrm{X}_{2}$ ).

\begin{tabular}{|c|c|c|c|c|c|}
\hline \multirow[b]{2}{*}{ compound } & \multirow{2}{*}{$\begin{array}{l}\mathrm{FcH} \\
(\mathrm{g})^{a}\end{array}$} & \multirow{2}{*}{$\begin{array}{l}{\left[\mathrm{FeCl}_{3}\right]} \\
(\mathrm{M})\end{array}$} & \multirow{2}{*}{$\begin{array}{l}\text { \# washes } \\
(\mathrm{mL})\end{array}$} & \multicolumn{2}{|c|}{ pure yield } \\
\hline & & & & (g) & $(\%)$ \\
\hline FcCl & 4.00 & 0.2 & $2 \times 200$ & 3.03 & 64 \\
\hline FcF & 0.91 & 0.1 & $3 \times 50$ & 0.32 & 32 \\
\hline $\mathrm{fcCl}_{2}$ & 9.30 & 3.0 & $3 \times 200$ & 12.7 & 75 \\
\hline $\mathrm{fcF}_{2}$ & 1.68 & 0.5 & $3 \times 50$ & 0.04 & 2 \\
\hline
\end{tabular}

${ }^{a}$ Indicative of reaction scale.

Preparation of fluorinated derivatives proved more challenging. We first noted established (non-explosive/non-toxic) routes for the preparation of aryl-fluorides from aryl-lithiums or aryl-magnesium bromides. ${ }^{19}$ In our hands however, reactions between $\mathrm{FcLi} / \mathrm{FcMgBr}^{20}$ and $\mathrm{N}$-chloromethyl-N'fluorotriethylenediammonium bis(tetrafluoroborate) (Selectfluor $\left.{ }^{\circledR}\right)$ or 1-fluoro-2,4,6-trimethylpyridinium triflate (FTMPT) provided no evidence of FcF. Whilst again no $\mathbf{F c F}$ was observed following combination of $\mathrm{FcMgBr}$ and $\mathrm{N}$ fluorobenzenesulfonimide (NFSI), the addition of NFSI to FcLi in $n$-hexane could provide pure FcF in $32 \%$ yield (following oxidative purification). Analogous conditions had been used in the preparation of 1-fluoro-2-(2-pyridyl)ferrocene, ${ }^{9}$ 1,2,3,4,5-pentafluoroferrocene, and FcF itself, albeit only obtained as a mixture comprising $5-20 \%$ ferrocene. ${ }^{6}$ We also observed the formation of 1-(phenylsulfonyl)ferrocene (amongst other unknown side-products), sometimes in quite significant (for example, $10 \%$ isolated) yields.

Following a similar approach, $\mathbf{f c F}_{\mathbf{2}}$ could be synthesized via addition of NFSI to fcLi ${ }_{2}$-TMEDA in diethyl ether, though yields were poor and variable (typically $<5 \%$ ). Whilst the material was frequently observed in crude ${ }^{1} \mathrm{H}$ NMR spectra it was readily lost during workup and purification through apparent decomposition in solution, or sublimation in vacuo. If instead, $1,1^{\text {'-dilithioferrocene }}{ }^{21}$ was prepared directly from 1,1'dibromoferrocene $^{14 \mathrm{c}}$ (eliminating other potentially reactive components such as TMEDA), the desired product was also observed in crude ${ }^{1} \mathrm{H}$ NMR spectra but yields and purity were not improved. Reactions in $n$-hexane (instead of diethyl ether) yielded only trace quantities of product, arguably due to the reduced solubility of NFSI and fcLi ${ }_{2}$-TMEDA in this solvent. If dimethyl ether was used (with even greater solubilizing power) the rate of reaction appeared to increase (more rapid color changes), but not the isolated yield. Future efforts towards fluorinated metallocenes might benefit from recent developments in transition metal-catalyzed fluorinations (for example, from phenols, ${ }^{22}$ aryl triflates, ${ }^{23}$ stannanes, ${ }^{24}$ boronic acids, ${ }^{25}$ silanes ${ }^{26}$ or iodides $\left.{ }^{27}\right){ }^{28}$

As with $\mathbf{F c C l}$ and $\mathbf{f c C l} \mathbf{l}_{2}$, aqueous $\mathrm{FeCl}_{3}$ was used to remove $\mathrm{FcH}$ and $\mathrm{FcH} / \mathbf{F c F}$ impurities from $\mathbf{F c F}$ and $\mathbf{f c F}_{\mathbf{2}}$, respectively (Table 1). Yields proved highly sensitive to the number of washes, and much lower $\mathrm{FeCl}_{3}$ concentrations had to be used compared to all other halogenated materials. This prompted further investigation of their electrochemical properties. 


\section{(b) Electrochemistry}

All materials were studied by solution voltammetry in $\mathrm{MeCN} / 0.1 \mathrm{M} \mathrm{NBu}_{4} \mathrm{PF}_{6}$, and exhibited essentially reversible behavior $\left(i_{\mathrm{pa}} / i_{\mathrm{pc}} \sim 1, i_{\mathrm{p}} \propto V_{\mathrm{s}}^{1 / 2}\right.$; data summarized in Table 2$)$. A comparison of equilibrium potentials for $\mathrm{FcX}$ and $\mathrm{fcX}_{2}$ show that $\mathrm{FcH}$ is easier to oxidize than $\mathrm{FcX}$, which in turn is easier to oxidize than $\mathrm{fcX}_{2}$ (for the same halide). This result holds true across both $\mathrm{FcX}$ and $\mathrm{fc} \mathrm{X}_{2}$ series $(\mathrm{X}=\mathrm{I}, \mathrm{Br}, \mathrm{Cl}, \mathrm{F})$ and is in line with the notion that as the number of electronwithdrawing substituents on the cyclopentadienyl ring increases, the complex becomes more difficult to oxidize (the HOMO in the parent ferrocene being largely metal-centered ${ }^{29}-$ also see the theoretical section). Within each series however, we observed that $\mathbf{F c F}$ and $\mathbf{f} \mathbf{c} \mathbf{F}_{2}$ are the complexes easiest to oxidize. This was surprising given that fluorine is widely considered the most electronegative of all elements ${ }^{30}$ (always more electronegative than the other halides it is actually the second most electronegative element, after neon, on the Allen scale ${ }^{31}$ ). Removal of electron density via inductive effects should render the Fe center more electron deficient (and so more difficult to remove an electron). ${ }^{32}$ Based on electronegativity alone, oxidation potentials following the order $\mathrm{F}>\mathrm{Cl}>\mathrm{Br}>\mathrm{I}$ might be expected, yet in the experimental data we see $\mathrm{Br} \sim \mathrm{Cl}>\mathrm{I}>$ $\mathrm{F}$ (within the $\sim 10 \mathrm{mV}$ experimental error). It is apparent that no simple correlation exists between substituent electronegativity and $E_{1 / 2}$ in these complexes. Studies elsewhere have made similar observations - 1,2,3,4,5-pentachloroferrocene $\left(\left[\mathrm{FeCp}\left(\mathrm{C}_{5} \mathrm{Cl}_{5}\right)\right], E^{0}=0.77 \mathrm{~V}\right.$ vs. $\mathrm{FcH} / \mathrm{FcH}^{+}$; reversible only at high scan rates $)^{33}$ is reportedly much more difficult to oxidize than 1,2,3,4,5-pentafluoroferrocene $\left(\left[\mathrm{FeCp}\left(\mathrm{C}_{5} \mathrm{~F}_{5}\right)\right], E_{0}=0.01\right.$ V vs. $\left.\mathrm{FcH} / \mathrm{FcH}^{+}\right) .{ }^{6}\left[\mathrm{FcB}\left(\mathrm{C}_{6} \mathrm{Cl}_{5}\right)_{2}\right]$ has also been observed to exhibit a higher equilibrium potential than $\left[\mathrm{FcB}\left(\mathrm{C}_{6} \mathrm{~F}_{5}\right)_{2}\right]\left(E_{1 / 2}=\right.$ $0.55 \mathrm{~V}$ vs. $0.45 \mathrm{~V}$, respectively; though the $\mathrm{C}_{6} \mathrm{Cl}_{5}$ group is in this case considered more electron withdrawing). ${ }^{34}$

Table 2. Electrochemical data. ${ }^{a}$

\begin{tabular}{llllll}
\hline compound & $E_{\mathrm{pa}} / \mathrm{V}$ & $E_{\mathrm{pc}} / \mathrm{V}$ & $\Delta \mathrm{E} / \mathrm{V}^{b}$ & $i_{\mathrm{pa}} / i_{\mathrm{pc}}{ }^{c}$ & $E_{1 / 2} / \mathrm{V}^{c}$ \\
\hline $\mathbf{F c F}$ & 0.063 & 0.134 & 0.071 & 0.99 & 0.098 \\
& $0.091^{d}$ & $0.118^{d}$ & - & $0.95^{d}$ & $0.105^{d}$ \\
$\mathbf{F c C l}$ & 0.130 & 0.194 & 0.064 & 1.01 & 0.162 \\
$\mathbf{F c B r}$ & 0.133 & 0.201 & 0.068 & 1.00 & 0.167 \\
$\mathbf{F c I}$ & 0.116 & 0.194 & 0.078 & 1.00 & 0.155 \\
$\mathbf{f c F}$ & 0.208 & 0.270 & 0.062 & 1.09 & 0.239 \\
$\mathbf{f c C l}_{2}$ & 0.286 & 0.346 & 0.060 & 0.99 & 0.316 \\
$\mathbf{f c B r}_{2}$ & 0.279 & 0.359 & 0.080 & 1.03 & 0.319 \\
$\mathbf{f c I}_{2}$ & 0.250 & 0.323 & 0.073 & 1.04 & 0.287 \\
\hline
\end{tabular}

${ }^{a}$ For scan rate $=0.1 \mathrm{Vs}^{-1} \cdot \mathrm{Bu}_{4} \mathrm{~N}^{+} \mathrm{PF}_{6}^{-}(0.1 \mathrm{M})$ in $\mathrm{MeCN}$; working electrode: glassy carbon; reference electrode, counter electrode: Pt. All potentials (error $= \pm 0.02 \mathrm{~V}$ ) assigned to the $\mathrm{Fe}^{2+} / \mathrm{Fe}^{3+}$ redox couple and reported relative to an internal $\mathrm{FcH} / \mathrm{FcH}^{+}$reference. Data from this work and reference $\left[{ }^{14 \mathrm{c}}\right] .{ }^{b}$ $\Delta E>0.060 \mathrm{~V}$ due to a small uncompensated solution resistance effect. ${ }^{c}$ From cyclic voltammetry experiments unless otherwise stated, where $E_{1 / 2}=1 / 2\left(E_{\mathrm{pa}}+E_{\mathrm{pc}}\right){ }^{d}$ From differential pulse voltammetry experiments, where $E_{1 / 2}=E_{\mathrm{pa} / \mathrm{pc}} \pm$ pulse height/2.
Several contributing factors to the ease of oxidation of fluoroferrocenes may be considered. These are discussed with reference to relevant spectroscopic and crystallographic data (see below). First we wondered if very electron-withdrawing substituents on the cyclopentadienyl anion $\left(\mathrm{Cp}^{-}\right)$ring might hamper its electron-donating ability, so weakening the $\mathrm{Cp}-\mathrm{Fe}$ bond and reducing the inductive electron-withdrawing effect felt at Fe. A weaker bond would however result in a longer $\mathrm{Cp}-\mathrm{Fe}$ distance, whereas the $\mathrm{X}$-ray crystal structure of $\left[\mathrm{FeCp}\left(\mathrm{C}_{5} \mathrm{~F}_{5}\right)\right]^{6}$ clearly shows the $\left(\mathrm{C}_{5} \mathrm{~F}_{5}\right)-\mathrm{Fe}$ bond is shorter (invalidating this theory). Likewise, any possibility of F-Fe orbital interactions - for example, agostic bonding/p orbital overlap (increasing the electron density at $\mathrm{Fe}$ ) - appears unlikely following the observation that the fluoride substituents are bent outwards and away from the ferrocene centre.

We next questioned the role resonance effects might play in stabilizing a positive charge, as increased charge delocalization would likely increase the stability of the oxidized product with respect to the reduced product in electrochemical equilibria. A useful discussion in this context was put forward by Richardson and co-workers who observed that $\left[\mathrm{Ru}\left(\mathrm{C}_{5} \mathrm{~F}_{5}\right) \mathrm{Cp}^{*}\right]$ was marginally easier to oxidize than $\left[\mathrm{Ru}\left(\mathrm{C}_{5} \mathrm{Cl}_{5}\right) \mathrm{Cp}^{*}\right]\left(E_{\mathrm{pa}}=\right.$ 1.07 vs. $1.11 \mathrm{~V}$, respectively; though in both cases the redox processes were either irreversible or quasi-reversible). ${ }^{35}$ Here the authors suggested that the similar $E_{\mathrm{pa}}$ values in these complexes could be rationalized using empirically determined substituent constants (such as those introduced by Hammett ${ }^{36}$ ). For $\mathrm{Cl}$ and $\mathrm{F}$ substituents the measured differences in polarizability, inductive/field effects (likely playing a negligible role here) and $\pi$ resonance effects on aromatic rings were considered to largely cancel each other out. Values of the Hammett $\left(\sigma_{\mathrm{p}}\right)$, field/inductive $(F)$ and resonance effect $(R)$ parameters for the halides - compiled by Hansch, Leo and Taft ${ }^{37}-$ are provided in Table 3 (generally, the more negative the value, the greater the stabilization of a positive charge). The biggest variations here can be seen to arise from the contributions of resonance effects, where the strong donating ability of fluorine is attributed to favorable $2 \mathrm{p}-2 \mathrm{p} \mathrm{F}-\mathrm{C}$ orbital interactions. It is interesting to note that some correlation between $R$ for halide substituents and $E_{1 / 2}$ for $\mathrm{FcX}$ and $\mathrm{fcX} \mathrm{X}_{2}$ can be observed (Figure 1 ), though deviations from the linear fit suggest resonance effects may not be the only contributing factor.

Table 3. Hammett $\left(\sigma_{\mathrm{p}}\right)$, field/inductive $(F)$ and resonance effect $(R)$ parameters for halide substituents. ${ }^{37}$

\begin{tabular}{llll}
\hline substituent & $\sigma_{\mathrm{p}}$ & $F$ & $R$ \\
\hline $\mathrm{F}$ & 0.06 & 0.45 & -0.39 \\
$\mathrm{Cl}$ & 0.23 & 0.42 & -0.19 \\
$\mathrm{Br}$ & 0.23 & 0.45 & -0.22 \\
$\mathrm{I}$ & 0.18 & 0.42 & -0.24 \\
\hline
\end{tabular}




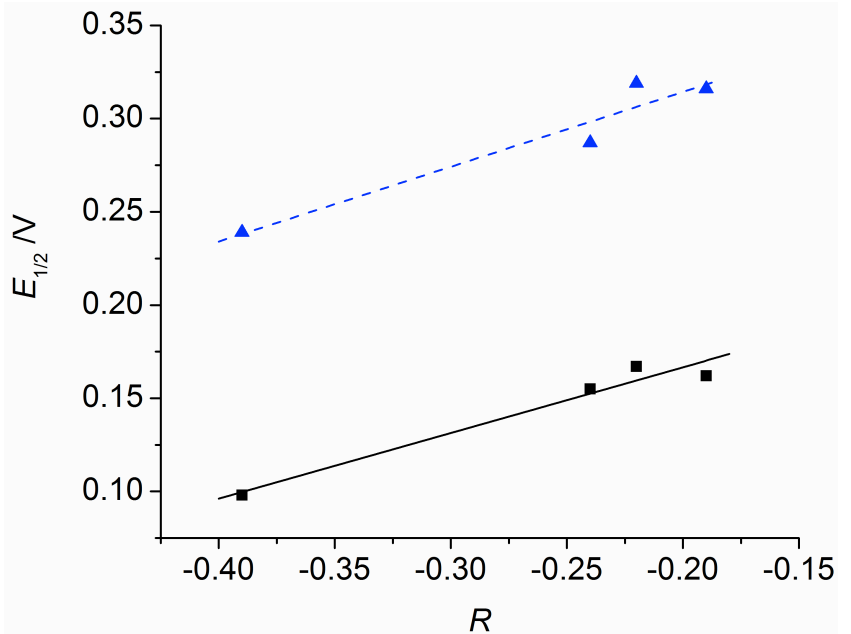

Figure 1. Resonance effect parameters $(R)$ for halide substituents plotted against $E_{1 / 2}$ for FcX (black squares, solid line) and $\mathrm{fcX}_{2}$ (blue triangles, dotted line).

Given that upon oxidation an electron is removed from the $\mathrm{HOMO}$, it is important also to consider changes to the ligand and metal character of frontier orbitals in ferrocenes upon $\mathrm{Cp}$ substitution. Previous work by Dowben and co-workers (concerning the photoelectron spectra of methylated and halogenated 1,1'-substituted ferrocenes) suggested that the greater the charge transfer from a $\mathrm{Cp}$ ring to its substituent, the greater the mixing of $\mathrm{Fe}_{\mathrm{x} 2-\mathrm{y} 2, \mathrm{xy}}$ and $\mathrm{Cp}\left(\mathrm{e}_{2 \mathrm{~g}}\right) \pi$ orbitals. ${ }^{38}$ Increased mixing results in a HOMO of higher binding energy, and so renders that complex more difficult to oxidize. Whilst 1,1'dimethylferrocene followed the anticipated trend, the authors noted that the experimentally determined HOMO (a1g) energy of $\mathbf{f C B r}_{2}$ (7.17 eV with respect to the vacuum level) was marginally higher than that of $\mathbf{f c C l}_{\mathbf{2}}(7.1 \mathrm{eV})$. As $\mathrm{Cl}$ has a higher electronegativity than $\mathrm{Br}$ it was argued (neglecting resonance effects) that in $\mathbf{~} \mathbf{f C C l} \mathbf{C}_{\mathbf{2}}$ there should be greater charge transfer from the $\mathrm{Cp}$ ring, and so greater $\mathrm{Fe} \mathrm{d}_{\mathrm{x} 2-\mathrm{y} 2, \mathrm{xy}}$ and $\mathrm{Cp}\left(\mathrm{e}_{2 \mathrm{~g}}\right) \pi$ mixing, and a lower HOMO energy (for $\mathrm{FcH}, E(\mathrm{a} 1 \mathrm{~g})=6.9 \mathrm{eV}$ ). Interestingly, this ${ }^{38}$ and similar observations ${ }^{6}$ have previously been attributed to experimental error. In light of the additional experimental evidence presented here (through systematic analysis of the $\mathrm{FcX}$ and $\mathrm{fcX} \mathrm{X}_{2}$ series), we suggest such properties should instead be accepted and rationalized.

\section{(c) NMR, UV-vis and IR spectroscopy}

In contrast to electrochemical observations, spectroscopic trends largely correlate with the electronegativity of substituents (Table 4). For example, the chemical shift difference between $H_{\alpha}$ and $H_{\beta}$ resonances increases for both the FcX and $\mathrm{fcX}_{2}$ series as $\mathrm{I}<\mathrm{Br}<\mathrm{Cl}<\mathrm{F}$. This occurs primarily from upfield shifts of all the $H_{\beta}$ resonances (up to $0.39 \mathrm{ppm}$ from that of the parent ferrocene $\mathrm{Cp}-H$ signal), with nuclei actually becoming more shielded with increasing substituent electronegativity. In contrast, the $H_{\alpha}$ and unsubstituted $\mathrm{Cp}$ ring resonances (where relevant) move downfield (up to $0.25 \mathrm{ppm}$ and 0.08 ppm from that of the parent ferrocene $\mathrm{Cp}-H$ signal, respectively). In the ${ }^{1} \mathrm{H}$ NMR spectra of the fluorinated derivatives it is also of note that the pseudo-triplets characteristic of a monosubstituted $\mathrm{Cp}$ ring are split further through coupling to the ${ }^{19} \mathrm{~F}$ nuclei - as indeed are the resonances of carbon nuclei on fluorine-substituted $\mathrm{Cp}$ rings (SI, Figures $\mathrm{S} 5,6$ and $\mathrm{S} 10,11$ ). The observed ${ }^{13} \mathrm{C}-{ }^{19} \mathrm{~F}$ coupling constants for fluorinated ferrocenes $\left({ }^{1} J_{\mathrm{C}-\mathrm{F}}=265.4,269.2 \mathrm{~Hz} ;{ }^{2} J_{\mathrm{C}-\mathrm{F}}=14.9,15.37 \mathrm{~Hz} ;{ }^{3} J_{\mathrm{C}-\mathrm{F}}=3.2\right.$ $\mathrm{Hz})$, closely match those measured in fluorobenzene $\left({ }^{1} J_{\mathrm{C}-\mathrm{F}}=\right.$ $245.0 \mathrm{~Hz} ;{ }^{2} J_{\mathrm{C}-\mathrm{F}}=21.1 \mathrm{~Hz} ;{ }^{3} J_{\mathrm{C}-\mathrm{F}}=2.5 \mathrm{~Hz}$ ). Perhaps unsurprisingly, the largest chemical shift changes in ${ }^{13} \mathrm{C}\left\{{ }^{1} \mathrm{H}\right\}$ spectra are with nuclei of carbon atoms directly bonded to halides. These become increasingly deshielded with increasing electronegativity of the substituent, whereas the $C_{\alpha}$ and $C_{\beta}$ nuclei become more shielded (as observed with $H_{\alpha}$ and $H_{\beta}$ ).

UV-vis spectroscopy was used to determine the optical properties of the series, where the relative energies of the HOMO-LUMO gap were of particular interest. Table 4 presents measured values of the unresolved ${ }^{1} \mathrm{~A}_{1 \mathrm{~g}} \rightarrow{ }^{1} \mathrm{E}_{1 \mathrm{~g}}$ and ${ }^{1} \mathrm{~A}_{1 \mathrm{~g}}$ $\rightarrow{ }^{1} \mathrm{E}_{2 \mathrm{~g}}$ spin-allowed d-d transition for each compound (occurring at $442 \mathrm{~nm}$ for the parent ferrocene in THF). ${ }^{39}$ Here only very small differences are observed, though in each case $\lambda_{\max }$ decreases from $\mathrm{F}<\mathrm{Cl}<\mathrm{Br}<\mathrm{I}<\mathrm{H}$ (increasing HOMOLUMO gap with increasing electronegativity).

The IR spectra of each compound exhibits adsorptions typical of the parent ferrocene, in addition to others associated with the halogen substituents (SI, Figure S15-18 and Table $\mathrm{S} 1)$. Sünkel et al. had previously associated peaks at 1506 and $939 \mathrm{~cm}^{-1}$ with the $\mathrm{C}_{5} \mathrm{~F}_{5}$ ring, and we note similar features in the spectra of both mono- and dihalo derivatives (FcF: 1468 and $928 \mathrm{~cm}^{-1}$; $\mathbf{f C F}_{2}$ : 1465 and $932 \mathrm{~cm}^{-1}$ ). With the aid of simulated spectra from first principle calculations (see the next section for more details) all bands could be fully assigned (SI, Table $\mathrm{S} 1)$. We find that the adsorptions at 1465-1506 correspond to C-F stretching, whereas those at $928-939 \mathrm{~cm}^{-1}$ are attributable to $\mathrm{C}-\mathrm{H} / \mathrm{F}$ deformation. Interestingly, $\mathrm{C}-\mathrm{X}$ bond stretches in halogenated ferrocenes follow the same trend in relative energies as the halobenzenes (where $\mathrm{C}-\mathrm{F}>\mathrm{C}-\mathrm{Cl}>\mathrm{C}-\mathrm{Br}>\mathrm{C}-\mathrm{I}$ ), yet typically occur at higher energies. For example, $\mathrm{C}$ $\mathrm{F}_{\text {(fluoroferrocene) }}=1468 \mathrm{~cm}^{-1}$ versus $\mathrm{C}-\mathrm{F}_{\text {(fluorobenzene) }}=1232 \mathrm{~cm}^{-1}$ (Figure S16-17). ${ }^{40}$ 
Table 4. Selected ${ }^{1} \mathrm{H}$ and ${ }^{13} \mathrm{C}\left\{{ }^{1} \mathrm{H}\right\} \mathrm{NMR},{ }^{a} \mathrm{UV}$-vis ${ }^{b}$ and $\mathrm{IR}^{c}$ spectroscopic data. ${ }^{d}$

\begin{tabular}{|c|c|c|c|c|c|c|c|c|c|}
\hline \multirow[b]{2}{*}{ compound } & \multicolumn{7}{|c|}{$\delta / \mathrm{ppm}$} & \multirow{2}{*}{$\begin{array}{l}\lambda_{\max } / \mathrm{nm} \\
\left(\varepsilon / \mathrm{M}^{-1} \mathrm{~cm}^{-1}\right)\end{array}$} & \multirow{2}{*}{$\begin{array}{l}\mathrm{Cp}-\mathrm{X} \\
/ \mathrm{cm}^{-1}\end{array}$} \\
\hline & $H_{\alpha}^{e}$ & $H_{\beta}^{e}$ & $\mathrm{C}_{5} \mathrm{H}_{5}$ & $C-\mathrm{X}$ & $C_{\alpha}$ & $C_{\beta}$ & $C_{5} \mathrm{H}_{5}$ & & \\
\hline $\mathrm{FcH}$ & - & - & 4.18 & - & - & - & 68.05 & $442.0(92)$ & - \\
\hline FcF & 4.31 & 3.79 & 4.26 & 135.76 & 56.18 & 61.15 & 69.44 & $435.5(96)$ & 1468 \\
\hline FcCl & 4.39 & 4.05 & 4.24 & 92.46 & 66.14 & 68.00 & 70.39 & $438.4(105)$ & $880^{f}$ \\
\hline $\mathrm{fcF}_{2}$ & 4.39 & 3.90 & - & 135.87 & 57.47 & 62.53 & - & $430.9(92)$ & 1465 \\
\hline $\mathrm{fcCl}_{2}$ & 4.42 & 4.13 & - & 93.28 & 68.53 & 70.11 & - & $436.1(241)$ & $\begin{array}{l}891^{f} \\
874^{f}\end{array}$ \\
\hline $\mathrm{fcI}_{2}$ & 4.37 & 4.18 & - & 40.42 & 72.41 & 77.72 & - & $440.5(214)$ & $864^{f}$ \\
\hline
\end{tabular}

${ }^{a}$ In $\mathrm{CDCl}_{3} .{ }^{b}$ In MeCN $(\sim 1-2 \mathrm{mM}) .{ }^{c}$ ATR. ${ }^{d}$ From this work and references $\left[{ }^{14 \mathrm{c}},{ }^{41}\right] .{ }^{e}$ Assignment based on assumption that $H_{\alpha}$ has a greater downfield shift than $H_{\beta} \cdot{ }^{f} \mathrm{C}-\mathrm{X}$ stretch combined with $\mathrm{C}-\mathrm{H}$ out-of-plane bending.

\section{(d) X-ray crystallography}

With the recent publication of a crystal structure for 1,1'diiodoferrocene, ${ }^{42}$ we sought to obtain the final three structures remaining in the $\mathrm{FcX}$ and $\mathrm{fcX}_{2}$ series. It was hoped structural comparisons might offer additional insights into the redox properties observed. Whilst data for $\mathbf{f c F}_{2}$ (Figure 2; SI, Figure S20) and $\mathbf{f c C l}_{\mathbf{2}}$ (Figure 3; SI, Figure S21) was readily obtained, attempts to get good quality data for FcF (SI, Figure 19) proved challenging - the structure proved to be highly disordered, and thus useless for geometric analysis (see the supporting information for more details). Unfortunately, this situation could not be improved regardless of whether crystals were grown from $n$-hexane, EtOH or toluene. Available experimental data is collected in Table 5, where calculated bond lengths and angles are included in square brackets for comparison. The latter are in excellent agreement with experiment, and likely well-representative of the actual parameters for FcF. The anticipated increase in $\mathrm{C}-\mathrm{X}$ bond length with $\mathrm{F}<\mathrm{Cl}$ $<\mathrm{Br}<\mathrm{I}$ is clear (in good agreement with IR spectroscopy). C$\mathrm{X}$ substituents in these metallocenes appear marginally bent away from the $\mathrm{Fe}$ centre - distances between the $\mathrm{Cp}$ plane and the halogen range from 0.023 to $0.136 \AA$. Unfortunately, no trends in line with the electrochemical behavior are easily determined from the structural information.

We also obtained the structure of $\mathbf{F c S O}_{2} \mathbf{P h}$ which was found to contain two crystallographically independent complexes, 3a-I and 3a-II, both shown in Figure 4 (see also SI, Figure S22).

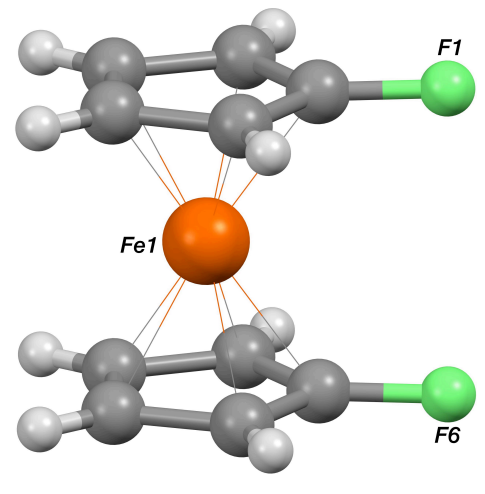

Figure 2. The crystal structure of $\mathbf{f C F}_{\mathbf{2}}$.

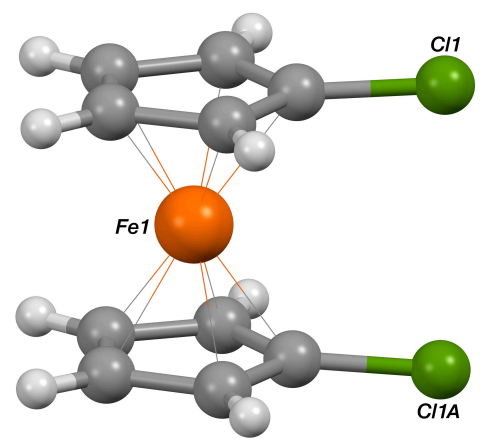

Figure 3. The crystal structure of the $C_{2}$-symmetric complex fcCl $\mathbf{l}_{2}$. The $C_{2}$ axis passes through the iron centre and bisects the $\mathrm{C} 11 \cdots \mathrm{C} 11 \mathrm{~A}$ vector. 
Table 5. Selected structural parameters. ${ }^{a}$

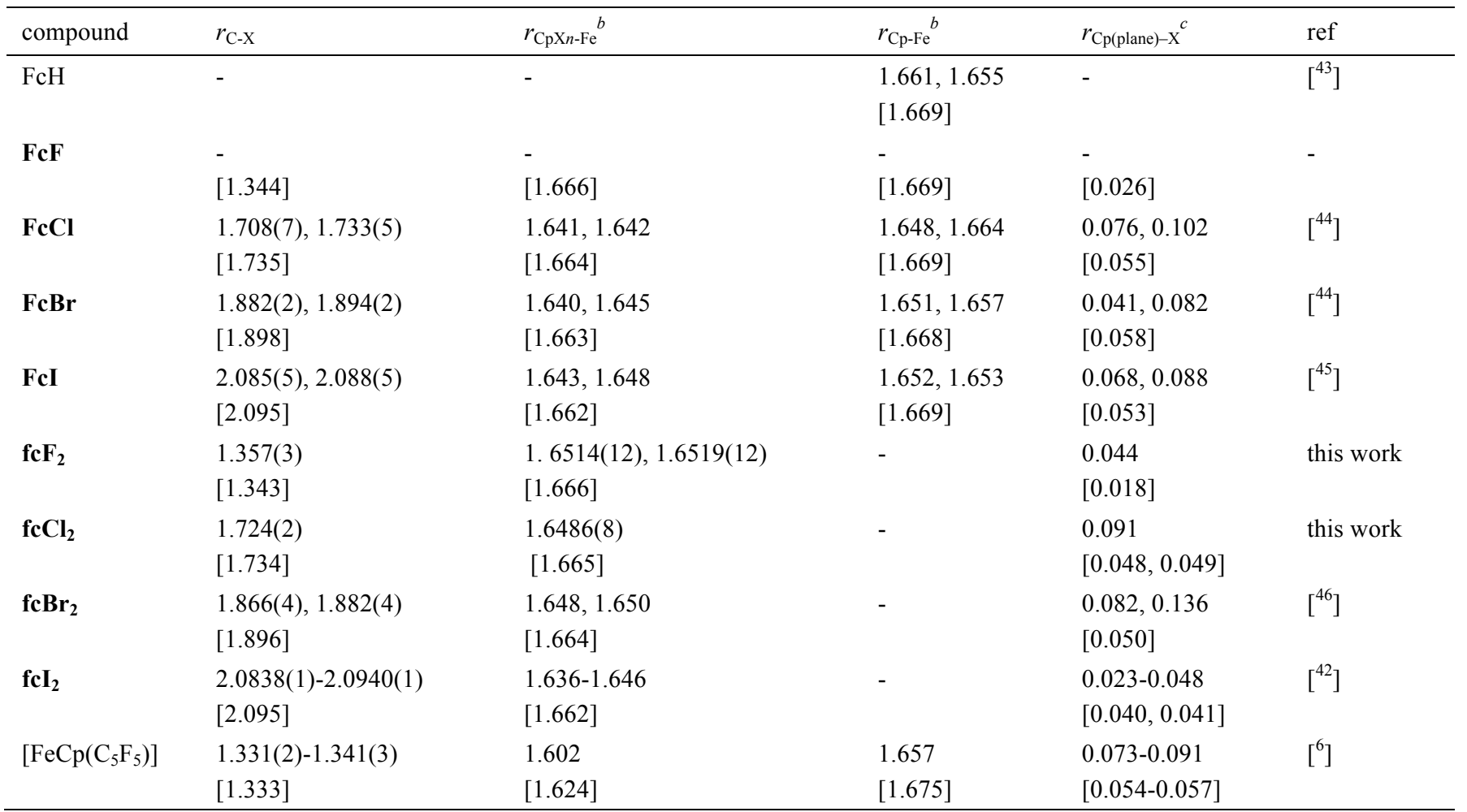

${ }^{a}$ Experimental bond lengths (in $\AA$ ), where available. Data in square brackets was obtained from first principles calculations. If multiple, non-identical distances were found, minimum and maximum values are provided to give an indication of the range. ${ }^{b} r_{\mathrm{CpX} n \text {-Fe }}=\mathrm{Fe}_{-}$ substituted $\mathrm{Cp}$ centroid distance. $r_{\mathrm{Cp}-\mathrm{Fe}}=\mathrm{Fe}-\mathrm{Cp}$ centroid distance. ${ }^{c}$ The distance between the $\mathrm{Cp}$ plane and $\mathrm{X}$.

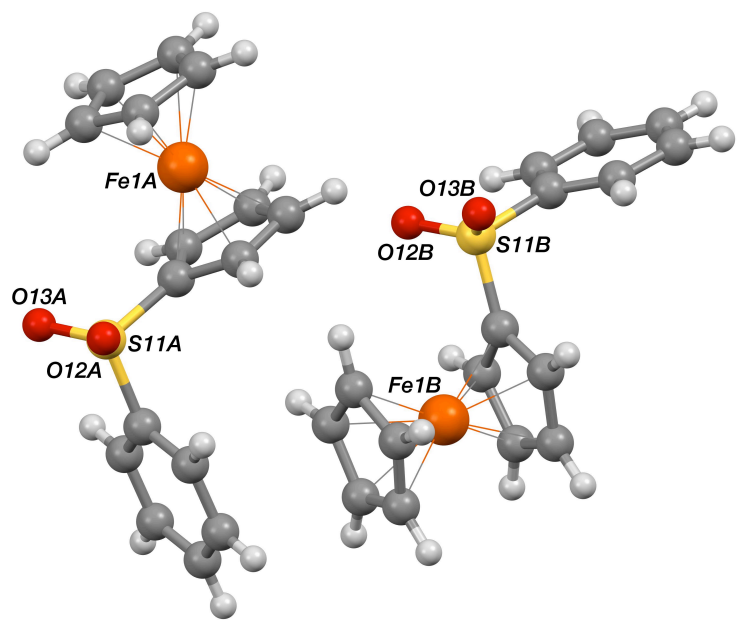

Figure 4. The crystal structure of $\mathbf{F C S O}_{2} \mathbf{P h}$ showing the two independent complexes $\mathbf{F c S O}_{2} \mathbf{P h}-\mathbf{A}$ and $\mathbf{F c S O} \mathbf{O}_{2} \mathbf{P h}-\mathbf{B}$.

\section{(e) First principles calculations}

In order to rationalize the ease with which fluorinated ferrocenes are oxidized we have performed density functional theory calculations. Energy levels and ionization energies have been determined for the isolated molecules and for solvated molecules using the conductor-like screening model (COSMO). All calculations have been carried out using the Turbomole programme. The molecular orbitals are expanded in an atom centered Gaussian basis set of TZVPP quality, ${ }^{47}$ electronic exchange and correlation described by the B3LYP hybrid-exchange functional and the D2 correction of Grimme is used to describe long range London dispersion interactions. $^{48}$

It is not unreasonable to expect that substitution with an electronegative element should make ferrocene more difficult to oxidize. This expectation is based on a simple model; as the HOMO in ferrocene is largely metal-centered and expected to be of $a_{1 g}$ character, ${ }^{29 b}$ the withdrawal of electrons from the ferrocene ring by electronegative substitution reduces Coulomb repulsion between the HOMO and the ring. The degree of stabilization is thus expected to be directly related to the electronegativity of the substituent. This trend has been observed, for example, in studies on fluorinated sydnones by Oshima et al. ${ }^{49}$

The computed HOMO eigenvalues in the first column of Table 6 show that the mono-fluorination of ferrocene stabilizes the HOMO as expected (by $0.29 \mathrm{eV}$ ). The monosubstitution of $\mathrm{Cl}, \mathrm{Br}$ or I produces further stabilization $(0.35$, 0.38 and $0.37 \mathrm{eV})$. This is consistent with the observed trend in the cyclic voltammetry measurements described above and suggests that electronegativity is not the dominant factor influencing oxidation. DFT eigenvalues of the isolated molecules are only a guide to the ionization energy (IE). The same trend is, however, maintained for the IE computed as the energy difference between the molecule and the positive ion (column 3 in Table 6). The trend is also preserved when the screening of the solvent is included using the COSMO approximation (columns 2 and 4 of Table 6). 
Table 6. HOMO and ionization energies (IE) of halogenated ferrocenes (TZVPP, B3LYP, COSMO for Acetonitrile ${ }^{50}$ ).

\begin{tabular}{lllll}
\hline compound & $\mathrm{HOMO} / \mathrm{eV}^{a}$ & $\mathrm{HOMO} / \mathrm{eV}^{b}$ & $\mathrm{IE} / \mathrm{eV}^{a}$ & $\mathrm{IE} / \mathrm{eV}^{b}$ \\
\hline $\mathrm{FcH}$ & -5.29 & -5.45 & 6.32 & 4.52 \\
$\mathbf{F c F}$ & -5.58 & -5.55 & 6.45 & 4.60 \\
$\mathbf{F c C l}$ & -5.64 & -5.58 & 6.46 & 4.67 \\
$\mathbf{F c B r}$ & -5.67 & -5.59 & 6.47 & 4.69 \\
$\mathbf{F c I}$ & -5.66 & -5.56 & 6.46 & 4.68 \\
$\mathbf{f c F}$ & -5.75 & - & - & - \\
$\mathbf{f c C l}_{2}$ & -5.85 & - & - & - \\
$\mathbf{f c B r}_{2}$ & -5.89 & - & - & - \\
$\mathbf{f c I}_{2}$ & -5.86 & - & - & - \\
{$\left[\mathrm{FeCp}\left(\mathrm{C}_{5} \mathrm{~F}_{5}\right)\right]$} & -6.36 & - & 7.15 & - \\
{$\left[\mathrm{Fe}\left(\mathrm{C}_{5} \mathrm{~F}_{5}\right)_{2}\right]$} & -7.11 & - & 7.82 & - \\
\hline$a$ & $\mathrm{After} 0 \mathrm{otimizaton}$ & & & \\
\hline
\end{tabular}

${ }^{a}$ After optimization. ${ }^{b}$ After optimization with COSMO.

Insight into the interaction affecting the HOMO energy can be gained by examining the computed electronic structure. Molecular orbital diagrams for ferrocene typically propose a LUMO of $\mathrm{e}_{1 \mathrm{~g}}$ symmetry ( $\mathrm{d}_{\mathrm{xz}}$ and $\mathrm{d}_{\mathrm{yz}}$ orbitals), a HOMO of $\mathrm{a}_{1 \mathrm{~g}}$ symmetry $\left(\mathrm{d}_{\mathrm{z} 2}\right.$ orbitals) and a HOMO-1 of $\mathrm{e}_{2 \mathrm{~g}}$ symmetry $\left(\mathrm{d}_{\mathrm{x} 2-\mathrm{y} 2}\right.$ and $d_{x y}$ orbitals). ${ }^{29 b}$ This is not, however, the picture that emerges from our DFT calculations. In the computed molecular orbitals the HOMO is composed predominantly of $\mathrm{e}_{2 \mathrm{~g}}\left(\mathrm{~d}_{\mathrm{x} 2}\right.$ $\left.\mathrm{y}_{2}, \mathrm{~d}_{\mathrm{yx}}\right)$ atomic orbitals and not of the $\mathrm{a}_{1 \mathrm{~g}}\left(\mathrm{~d}_{\mathrm{z} 2}\right)$ orbitals. In contrast to the $\mathrm{a}_{1 \mathrm{~g}}\left(\mathrm{~d}_{\mathrm{x}}{ }^{2}\right)$ orbitals, the $\mathrm{e}_{2 \mathrm{~g}}\left(\mathrm{~d}_{\mathrm{x} 2-\mathrm{y} 2}, \mathrm{~d}_{\mathrm{yx}}\right)$ atomic orbitals lie planar to the $\mathrm{Cp}$ rings. The energy of the HOMO is thus influenced by a combination of electrostatic repulsion and by the hybridization of the planar $\mathrm{d}_{\mathrm{x} 2-\mathrm{y} 2}$ and $\mathrm{d}_{\mathrm{yx}}$ orbitals with the $\mathrm{Cp}$ ring orbitals. Withdrawal of electrons from the ring by electronegative substitution reduces hybridization and thus destabilizes the HOMO. The position of the HOMO is determined by a balance between the competing influence of changes in electrostatic repulsion and covalent stabilization. $\mathrm{Cl}, \mathrm{Br}$ and $\mathrm{I}$ are less electronegative then $\mathrm{F}$ and therefore mono-substitution with these elements leads to less reduction of the covalent stabilization. Consequently, in comparison to mono-fluorination, the HOMO is further stabilized (columns 2 and 3 of Table 6).

The molecular orbital compositions and bond orders give further insight into the stabilization mechanism (Tables 7 and 8). The molecular orbital compositions show that the HOMO becomes less metal-centered upon halogenation (column 2 of Table 7), thus showing reduced electrostatic repulsion. The mono-fluorination of ferrocene leads to the least metalcentered HOMO (column 2 of Table 7). It is only for monoiodinated ferrocene that the halogen atom gives a significant contribution to the HOMO and HOMO-1 orbitals (column 5 of Table 7). It appears that the greater polarizability of iodine leads to an enhanced hybridization with the metal centre. In particular, mono-fluorinated and mono-iodinated ferrocene show significant contributions of the $\mathrm{Cp}$ rings to the $\mathrm{HOMO}$ (column 3 of Table 7). This can be attributed to $\Pi$-resonance effects of the aromatic system and is in accordance with the experimental observation that fluorine and iodine show the highest resonance effects of all halide substituents (column 4 of Table 3 ).
Table 7. Molecular orbital compositions for halogenated ferrocenes (TZVPP, B3LYP, HOMO: $\mathrm{e}_{2 \mathrm{~g}}$, HOMO-1: $\mathrm{a}_{1 \mathrm{~g}}$ ).

\begin{tabular}{lllll}
\hline & \multicolumn{4}{c}{ HOMO (HOMO-1) $/ \%$} \\
\cline { 2 - 5 } compound & $\mathrm{Fe}$ & $\mathrm{C}$ & $\mathrm{H}$ & $\mathrm{X}$ \\
\hline FcH & $85.5(91)$ & $14(6)$ & $0.5(3)$ & - \\
FcF & $76.5(87)$ & $22.5(9)$ & $0.5(3)$ & $0.5(1)$ \\
FcCl & $80(88)$ & $18(8)$ & $0.5(3)$ & $1.5(1)$ \\
FcBr & $79.5(82)$ & $17.5(10)$ & $0.5(3)$ & $2(5)$ \\
FcI & $77.5(42)$ & $19(23)$ & $0(2)$ & $4(33)$ \\
\hline
\end{tabular}

The computed bond orders also reflect changes in covalent stabilization; the mono-iodinated and -fluorinated ferrocenes have lower bond orders than the other haloferrocenes (column 2, Table 8).

Table 8. Bond orders for Fe-Cp (TZVPP, B3LYP).

\begin{tabular}{ll}
\hline compound & Fe-Cp bond order \\
\hline FcH & 1.976 \\
FcF & 2.070 \\
FcCl & 2.074 \\
FcBr & 2.076 \\
FcI & 2.065 \\
\hline
\end{tabular}

In addition to the electrostatic repulsion and covalent stabilization the size and polarizability of the halogens may also affect the IE. Withdrawal of electrons from the ring by electronegative substitution increases the electrostatic through space repulsion between the halogen atom and the iron center. Solvent molecules may screen this interaction. However, with increasing halogen size, this screening effect is minimized through steric hindrance of the screening molecules. Therefore, the size of the halogen also influences the balance between electrostatic through space repulsion and covalent stabilization. As a consequence, in comparison to monochlorination, mono-bromination makes oxidation harder to achieve (column 6 of Table 2; columns 4 and 5 of Table 6). This model successfully accounts for the trends in both the mono- and bi-halogenated ferrocenes. The HOMO energies of the bi-halogenated ferrocenes show the same trend as the HOMO energies of the mono-halogenated ferrocenes (column 2 of Table 6). However, in comparison to the monohalogenated ferrocenes, the HOMO energies of the bihalogenated ferrocenes are marginally lower, thus generally showing a higher stabilization. This is in accordance with the experimental observation that the bi-halogenated ferrocenes are generally harder to oxidise than the mono-halogenated 7 ferrocenes (column 5 of Table 2). 
The experimental observation that penta-fluorination further reduces the IE is not consistent with this model or with the computed IE (column 2 of Table 6). This observation has, however, been reported in a single publication ${ }^{6}$ and needs further verification.

\section{CONCLUSION}

All of the halo and 1,1'-dihaloferrocenes $(\mathrm{X}=\mathrm{I}, \mathrm{Br}, \mathrm{Cl}, \mathrm{F})$ have now been prepared and characterized within a single laboratory. In contrast to the findings of previous studies, we demonstrate that all these materials may be obtained in high purity using straightforward, readily available methods such as oxidative purification (here extended to $\mathrm{Cl}$ and $\mathrm{F}$ derivatives) and column chromatography. With this approach it proves possible to separate compounds with only $\sim 100 \mathrm{mV}$ differences in $E_{1 / 2}$ (for example, $\mathrm{FcH}$ and $\mathrm{FcF}$ ). Solution voltammetry and first principle studies confirm the perhaps counterintuitive result that ferrocenes with increasingly electronwithdrawing substituents become first harder, then easier to oxidize. A theoretical model, which explains the observed trends, has been introduced. In the quest for high-oxidization resistant metallocenes this work has important ramifications, not least suggesting that the most difficult to oxidize perhaloferrocenes have already been prepared (decachloroferrocene $^{11 b, 13}$ and decabromoferrocene ${ }^{51}$ ).

\section{EXPERIMENTAL}

\section{General considerations}

All reactions were performed under an atmosphere of nitrogen. Solvents used in reactions were sparged with nitrogen and dried with alumina beads or Q5 copper catalyst on molecular sieves, where appropriate. Mass spectrometry analyses were conducted by the Mass Spectrometry Service, Imperial College London. ${ }^{1} \mathrm{H},{ }^{13} \mathrm{C}\left\{{ }^{1} \mathrm{H}\right\}$ and ${ }^{19} \mathrm{~F}\left\{{ }^{1} \mathrm{H}\right\}$ NMR were recorded on a Bruker $400 \mathrm{MHz}$ spectrometer and referenced to the residual solvent peaks of $\mathrm{CDCl}_{3}$ at 7.26 and $77.16 \mathrm{ppm}$, or externally to $85 \%$ phosphoric acid $(0.00 \mathrm{ppm})$, respectively. UVvis and IR spectra were recorded on a PerkinElmer LAMBDA $25 \mathrm{UV} /$ vis spectrophotometer or a PerkinElmer Spectrum 100 FT-IR spectrometer, respectively. Microanalyses were carried out by Stephen Boyer of the Science Centre, London Metropolitan University. $\mathbf{F c I}, \mathbf{F c B r}, \mathbf{f c I}_{2}$ and $\mathbf{f c B r}_{\mathbf{2}}$ were prepared using literature procedures or purchased from Sigma-Aldrich, UK. ${ }^{14 c}$ All other reagents were commercially available and used as received.

Cyclic voltammograms were recorded under an atmosphere of argon in $\mathrm{MeCN} / 0.1 \mathrm{M}^{n} \mathrm{Bu}_{4} \mathrm{NPF}_{6}$ on a CHI760C potentiostat ( $\mathrm{CH}$ Instruments, Austin, Texas) with a glassy carbon disc as working electrode (diameter $=2.5 \mathrm{~mm}$ ), and Ptwire as reference and counter electrodes respectively. Analyte solutions were between $0.1-1 \mathrm{mM}$. Potentials are reported relative to an internal $[\mathrm{FcH}]^{+} /[\mathrm{FcH}]$ reference.

\section{Chloroferrocene $(\mathrm{FcCl})^{18}$}

A mixture of ferrocene $(4.00 \mathrm{~g}, 21.5 \mathrm{mmol}, 1 \mathrm{eq})$, potassium tert-butoxide (0.03 g, $2.68 \mathrm{mmol}, 0.12$ eq.) and THF (120 mL) was stirred in an oven-dried $250 \mathrm{~mL}$ three-necked flask and cooled to $-78^{\circ} \mathrm{C}$ (acetone/dry ice). $1.9 \mathrm{M}{ }^{t} \mathrm{BuLi}$ in pentane $(23$ $\mathrm{mL}, 43.2 \mathrm{mmol}, 2$ eq.) was added dropwise and the mixture vigorously stirred for $2 \mathrm{~h}$. To the resulting orange suspension was added hexachloroethane (7.65 g, $32.3 \mathrm{mmol}, 1.5 \mathrm{eq}$.$) por-$ tionwise against nitrogen. After stirring for a further $30 \mathrm{~min}$ at $-78^{\circ} \mathrm{C}$, the mixture was allowed to warm slowly to ambient temperature by not adding dry ice. The dark orange solution was then carefully quenched with water $(\sim 10 \mathrm{~mL})$, extracted with $\mathrm{CH}_{2} \mathrm{Cl}_{2}$ and solvent removed.

The crude product was extracted into $n$-hexane $(\sim 300 \mathrm{~mL})$, and washed with $0.2 \mathrm{M}$ aqueous $\mathrm{FeCl}_{3}(2 \times 200 \mathrm{~mL})$. When $\mathrm{FcH}$ had been removed (composition monitored by ${ }^{1} \mathrm{H}$ NMR spectroscopy between washings), the organic phase was extracted with water until the washings were colorless, dried over $\mathrm{MgSO}_{4}$ and filtered (50 g silica/n-hexane). The solution was dried in vacuo to yield pure $\mathrm{FcCl}$ as an orange crystalline solid (3.03 g, $64 \%)$. ${ }^{1} \mathrm{H}$ NMR (400 $\left.\mathrm{MHz}, \mathrm{CDCl}_{3}\right): \delta(\mathrm{ppm})$ 4.05 (pseudo-t, $2 \mathrm{H}, \mathrm{Cp}-H, J_{\mathrm{HH}}=1.83$ and $1.85 \mathrm{~Hz}$ ), 4.24 (s, $5 \mathrm{H}, \mathrm{Cp}-H$ ) 4.39 (pseudo-t, $2 \mathrm{H}, \mathrm{Cp}-H, J_{\mathrm{HH}}=1.89$ and 1.90 $\mathrm{Hz}) .{ }^{13} \mathrm{C}\left\{{ }^{1} \mathrm{H}\right\}$ NMR $\left(101 \mathrm{MHz}, \mathrm{CDCl}_{3}\right): \delta(\mathrm{ppm}) 66.14(2 \mathrm{C}$, $\mathrm{Cp}-\mathrm{Cl}, \mathrm{CH}), 68.00(2 \mathrm{C}, \mathrm{Cp}-\mathrm{Cl}, \mathrm{CH}), 70.39$ (5C, Cp, CH), $92.46(1 \mathrm{C}, \mathrm{Cp}-\mathrm{Cl}, \mathrm{CCl})$. HR-MS EI+: $m / z 219.9735\left([\mathrm{M}]^{+}\right.$ calc.: 219.9742). (Found: C, 54.39; H, 4.13. Calc. for $\mathrm{C}_{10} \mathrm{H}_{9} \mathrm{FeCl}$ : C, 54.45; H, 4.12\%).

\section{Fluoroferrocene $\quad(F c F)^{1 d, 6-8}$ and 1- (phenylsulfonyl)ferrocene ( $\left.\mathrm{FCSO}_{2} \mathrm{Ph}\right)^{52}$}

A mixture of ferrocene $(0.911 \mathrm{~g}, 4.90 \mathrm{mmol}, 1 \mathrm{eq}$.$) , potassium$ tert-butoxide $(0.067 \mathrm{~g}, 0.60 \mathrm{mmol}, 0.12 \mathrm{eq}$.$) and THF (15 \mathrm{~mL})$ was stirred in an oven-dried flask and cooled to $-78{ }^{\circ} \mathrm{C}$ (acetone/dry ice). $1.7 \mathrm{M}{ }^{t} \mathrm{BuLi}$ in pentane $(5.8 \mathrm{~mL}, 9.86 \mathrm{mmol}, 2$ eq.) was added dropwise over $\sim 20 \mathrm{~min}$ and the mixture vigorously stirred for $2 \mathrm{~h}$. To the resulting orange suspension was added $\mathrm{N}$-fluorobenzenesulfonimide (2.288 g, $7.26 \mathrm{mmol}, 1.5$ eq.) portionwise against nitrogen (CARE: effervescent reaction may result). After stirring for a further $30 \mathrm{~min}$ at $-78^{\circ} \mathrm{C}$, the mixture was allowed to warm slowly to ambient temperature overnight by not adding dry ice. The yellow-brown suspension was then carefully quenched with water $(10 \mathrm{~mL})$, and filtered through Celite using $\mathrm{CH}_{2} \mathrm{Cl}_{2}$. The solution was washed with water $(1 \mathrm{x} 40 \mathrm{~mL})$, and the aqueous phase extracted with $\mathrm{CH}_{2} \mathrm{Cl}_{2}(2 \times 25 \mathrm{~mL})$. The combined organic layers were dried over $\mathrm{MgSO}_{4}$, filtered through Celite and solvent removed.

Solid material was dissolved in $\mathrm{CH}_{2} \mathrm{Cl}_{2}(\sim 100 \mathrm{~mL})$ and washed with $0.1 \mathrm{M}$ aqueous $\mathrm{FeCl}_{3}(3 \times 50 \mathrm{~mL})$. When $\mathrm{FcH}$ had been removed (composition monitored by ${ }^{1} \mathrm{H}$ NMR spectroscopy between washings), the organic phase was extracted with water until the washings were colorless, dried over $\mathrm{MgSO}_{4}$ and filtered through Celite. The residue was preabsorbed on silica and purified by column chromatography (silica; $n$-hexane $\rightarrow \mathrm{CH}_{2} \mathrm{Cl}_{2} / n$-hexane [3:1]). Combined fractions from the first yellow band (eluting with $n$-hexane) yielded FcF as a light yellow solid after solvent removal $(0.316 \mathrm{~g}$, 32\%). ${ }^{1} \mathrm{H}$ NMR (400 MHz, $\mathrm{CDCl}_{3}$ ): $\delta$ (ppm) 3.79 (d pseudo-t, $\left.2 \mathrm{H}, \mathrm{Cp}-H, J_{\mathrm{HF}}=1.47 \mathrm{~Hz}\right), 4.26(\mathrm{~s}, 5 \mathrm{H}, \mathrm{Cp}-H), 4.30$ (d pseudo-t, $2 \mathrm{H}, \mathrm{Cp}-H, J_{\mathrm{HF}}=2.72 \mathrm{~Hz}, J_{\mathrm{HH}}=\sim 2.04$ and $\left.\sim 2.05 \mathrm{~Hz}\right)$. ${ }^{13} \mathrm{C}\left\{{ }^{1} \mathrm{H}\right\}$ NMR $\left(101 \mathrm{MHz}, \mathrm{CDCl}_{3}\right): \delta(\mathrm{ppm}) 56.18(\mathrm{~d}, 2 \mathrm{C}, \mathrm{Cp}-$ $\left.\mathrm{F}, \mathrm{CH}_{\alpha}, J_{\mathrm{C}-\mathrm{F}}=15.4 \mathrm{~Hz}\right), 61.15\left(\mathrm{~d}, 2 \mathrm{C}, \mathrm{Cp}-\mathrm{F}, C \mathrm{H}_{\beta}, J_{\mathrm{CF}}=3.2\right.$ $\mathrm{Hz}), 69.44$ (s, 5C, Cp, CH), $135.76\left(\mathrm{~d}, 1 \mathrm{C}, \mathrm{Cp}-\mathrm{F}, C \mathrm{~F}, J_{\mathrm{CF}}=\right.$ $265.4 \mathrm{~Hz}) .{ }^{19} \mathrm{~F}\left\{{ }^{1} \mathrm{H}\right\}$ NMR $\left(377 \mathrm{MHz}, \mathrm{CDCl}_{3}\right): \delta(\mathrm{ppm})-188.8$ (s, Cp-F). HR-MS EI+: $m / z 204.0051$ ([M]+ calc.: 204.0038). (Found: C, 58.72; H, 4.35. Calc. for $\mathrm{C}_{10} \mathrm{H}_{9} \mathrm{FeF}$ : C, 58.85; H, $4.45 \%)$.

Additional colored bands were observed with increasing proportion of $\mathrm{CH}_{2} \mathrm{Cl}_{2}$ in the eluent, with some fractions identified as comprising pure 1-(phenylsulfonyl)ferrocene $(\mathrm{Rf}=$ 0.24; silica, $\mathrm{CH}_{2} \mathrm{Cl}_{2} / n$-hexane [8:2]). This was isolated as an orange crystalline solid after solvent removal (0.156 g, 10\%). Crystals suitable for X-ray diffraction were formed through8 slow evaporation of a $\mathrm{CH}_{2} \mathrm{Cl}_{2} / n$-pentane solution. ${ }^{1} \mathrm{H} \mathrm{NMR}$ 
(400 MHz, $\mathrm{CDCl}_{3}$ ): $\delta$ (ppm) 4.40 (br pseudo-t, $2 \mathrm{H}, \mathrm{Cp}-H$ ), 4.49 (s, 5H, Cp-H), 4.68 (br pseudo-t, $2 \mathrm{H}, \mathrm{Cp}-H$ ), 7.40-7.54 $(\mathrm{m}, 3 \mathrm{H}, \mathrm{Ph}-H), 7.84(\mathrm{~d}, 2 \mathrm{H}, \mathrm{Ph}-H, J=7.82 \mathrm{~Hz}) .{ }^{13} \mathrm{C}\left\{{ }^{1} \mathrm{H}\right\}$ NMR $\left(101 \mathrm{MHz}, \mathrm{CDCl}_{3}\right): \delta(\mathrm{ppm}) 69.39$ (2C, Cp-R, CH), 70.89 (5C, Cp, CH), 71.28 (2C, Cp-R, CH), 90.37 (1C, Cp-R, $C \mathrm{R}), 126.81\left(2 \mathrm{C}, \mathrm{Ph}-\mathrm{R}, C \mathrm{H}_{o}\right), 129.13\left(2 \mathrm{C}, \mathrm{Ph}-\mathrm{R}, C \mathrm{H}_{m}\right)$, $132.68\left(1 \mathrm{C}, \mathrm{Ph}-\mathrm{R}, C \mathrm{H}_{p}\right), 143.21$ (1C, Ph-R, CR). HR-MS $\mathrm{EI}+: m / z 326.0073$ ([M]+ calc. for $\left.\mathrm{C}_{16} \mathrm{H}_{14} \mathrm{FeO}_{2} \mathrm{~S}: 326.0064\right)$.

\section{1,1'-Dichloroferrocene $\left(\mathrm{fcCl}_{2}\right)^{5 a}$}

A mixture of ferrocene ( $9.30 \mathrm{~g}, 50 \mathrm{mmol}, 1 \mathrm{eq}$.$) , TMEDA (18$ $\mathrm{mL}, 125 \mathrm{mmol}, 2.5$ eq.) and $n$-hexane $(60 \mathrm{~mL})$ was stirred in an oven-dried $250 \mathrm{~mL}$ three-necked flask and cooled to $0^{\circ} \mathrm{C}$ (ice-bath). $2.5 \mathrm{M}^{n} \mathrm{BuLi}$ in hexanes (44 mL, $110.0 \mathrm{mmol}, 2.2$ eq.) was added portionwise and the mixture slowly raised to ambient temperature with stirring overnight. The resulting bright orange suspension (1,1'-dilithioferrocene-TMEDA) was cooled to $-78^{\circ} \mathrm{C}$ (acetone/dry ice), whereby hexachloroethane (26.0 g, $110 \mathrm{mmol}, 2.2$ eq.) was added over $\sim 2 \mathrm{~min}$ against nitrogen. The reaction mixture was allowed to warm slowly to ambient temperature by not adding dry ice and stirred overnight, whereby it was quenched with water $(\sim 20 \mathrm{~mL})$ and extracted with diethyl ether. Combined extracts were dried in vacuo.

The crude product was extracted into $n$-hexane $(\sim 300 \mathrm{~mL})$, filtered through Celite and washed successively with $3.0 \mathrm{M}$ aqueous $\mathrm{FeCl}_{3}(3 \times 200 \mathrm{~mL})$. When $\mathrm{FcH}$ and $\mathbf{~ F c C l}$ contaminants had been removed (composition monitored by ${ }^{1} \mathrm{H}$ NMR spectroscopy between washings), the organic phase was extracted with water until the washings were colorless, dried over $\mathrm{MgSO}_{4}$, and filtered (50 g silica/ $n$-hexane). The solution was dried in vacuo to yield pure $\mathbf{f} \mathbf{C C l}_{\mathbf{2}}$ as a yellow solid (12.7 g, $75 \%$ ). Crystals suitable for X-ray diffraction were grown by cooling a concentrated $n$-hexane solution (from $\sim 20^{\circ} \mathrm{C}$ to $5^{\circ} \mathrm{C}$ ). ${ }^{1} \mathrm{H}$ NMR $\left(400 \mathrm{MHz}, \mathrm{CDCl}_{3}\right.$ ): $\delta$ (ppm) 4.13 (pseudo-t, $4 \mathrm{H}, \mathrm{Cp}-H, J_{\mathrm{HH}}=1.96$ and $2.28 \mathrm{~Hz}$ ), 4.42 (pseudo-t, $4 \mathrm{H}, \mathrm{Cp}-$ $H, J_{\mathrm{HH}}=2.03$ and $\left.2.13 \mathrm{~Hz}\right) .{ }^{13} \mathrm{C}\left\{{ }^{1} \mathrm{H}\right\} \mathrm{NMR}(101 \mathrm{MHz}$, $\left.\mathrm{CDCl}_{3}\right): \delta(\mathrm{ppm}) 68.53(4 \mathrm{C}, \mathrm{Cp}, \mathrm{CH}), 70.11(4 \mathrm{C}, \mathrm{Cp}, \mathrm{CH})$, 93.28 (2C, Cp, CCl). HR-MS EI+: $m / z 253.9367$ ([M] $]^{+}$calc.: 253.9362). (Found: $\mathrm{C}, 47.17 ; \mathrm{H}, 3.23$. Calc. for $\mathrm{C}_{10} \mathrm{H}_{8} \mathrm{FeCl}_{2}$ : C, 47.09; H, 3.16\%).

\section{1,1'-Difluoroferrocene $\left(\mathrm{fcF}_{2}\right)^{5 \mathrm{c}}$}

A mixture of ferrocene (1.678 g, $9.02 \mathrm{mmol}, 1 \mathrm{eq}$.$) , TMEDA$ (3.4 mL, $22.68 \mathrm{mmol}, 2.5$ eq.) and $n$-hexane ( $8.5 \mathrm{~mL})$ was stirred in an oven-dried flask and cooled to $0^{\circ} \mathrm{C}$ (ice-bath). 2.5 $\mathrm{M}^{n} \mathrm{BuLi}$ in hexanes (7.9 mL, $19.75 \mathrm{mmol}, 2.2$ eq.) was added portionwise and the mixture slowly raised to ambient temperature with stirring overnight. (NOTE: the remaining steps were completed within the same day to minimize product decomposition.) The resulting bright orange suspension (1,1'dilithioferrocene-TMEDA) was isolated by cannula filtration, re-suspended in diethyl ether $(22 \mathrm{~mL})$ and cooled to $-78^{\circ} \mathrm{C}$ (acetone/dry ice) whereby N-fluorobenzenesulfonimide (6.257 g, 19.84 mmol, 2.2 eq.) was added over $\sim 2$ min against nitrogen. The reaction mixture was stirred below $-70^{\circ} \mathrm{C}$ for $3 \mathrm{~h}$ then allowed to warm slowly to ambient temperature by not adding dry ice. After $\sim 15 \mathrm{~min}$ at room temperature the yellow suspension darkens with formation of precipitate. This mixture was cooled in an ice-bath and quenched with water $(4 \mathrm{~mL})$. Extraction with diethyl ether and $n$-hexane and filtration through alumina (Brockman grade II) provided a dark orange solution.

After reducing the solution in volume to $\sim 200 \mathrm{~mL}$, it was washed with $0.5 \mathrm{M}$ aqueous $\mathrm{FeCl}_{3}(3 \times 50 \mathrm{~mL})$. When $\mathrm{FcH}$ and $\mathbf{F c F}$ contaminants had been removed (composition moni- tored with ${ }^{1} \mathrm{H}$ NMR between washings), the organic phase was extracted with water until the washings were colorless, and reduced in volume to $<5 \mathrm{~mL}$. The crude product was purified using column chromatography (silica; $n$-pentane), collecting the first yellow band. The majority of solvent was carefully removed under reduced pressure (CARE: $\mathbf{f c F}_{\mathbf{2}}$ is readily sublimed in vacuo), then a concentrated solution further dried in air to yield $\mathbf{f c F}_{\mathbf{2}}$ as an orange-yellow crystalline solid $(0.041 \mathrm{~g}$, $2 \%$ ). Crystals suitable for X-ray diffraction were grown by slow evaporation of a $n$-hexane solution. ${ }^{1} \mathrm{H}$ NMR $(400 \mathrm{MHz}$, $\left.\mathrm{CDCl}_{3}\right): \delta$ (ppm) 3.90 (d pseudo-t, $4 \mathrm{H}, \mathrm{Cp}-H, J_{\mathrm{HF}}=1.20 \mathrm{~Hz}$ ), 4.39 (d pseudo-t, $4 \mathrm{H}, \mathrm{Cp}-H, J_{\mathrm{HF}}=2.20 \mathrm{~Hz}, J_{\mathrm{HH}}=\sim 2.18$ and $\sim 2.27 \mathrm{~Hz}) .{ }^{13} \mathrm{C}\left\{{ }^{1} \mathrm{H}\right\}$ NMR (126 MHz, $\mathrm{CDCl}_{3}$ ): $\delta$ (ppm) 57.47 (d, $4 \mathrm{C}, \mathrm{Cp}-\mathrm{F}, \mathrm{CH}_{\alpha}, J_{\mathrm{CF}}=14.9 \mathrm{~Hz}$ ), 62.53 (br. s, $4 \mathrm{C}, \mathrm{Cp}, \mathrm{CH}_{\beta}$ ), 135.9 (d, 2C, Cp-F, CF, $\left.J_{\mathrm{CF}}=269.2 \mathrm{~Hz}\right) .{ }^{19} \mathrm{~F}\left\{{ }^{1} \mathrm{H}\right\}$ NMR $(377$ $\left.\mathrm{MHz}, \mathrm{CDCl}_{3}\right): \delta(\mathrm{ppm})-188.0(\mathrm{~s}, 2 \mathrm{~F}, \mathrm{Cp}-F)$. HR-MS ES+: $m / z$ $221.9949\left([\mathrm{M}]^{+}\right.$calc.: 221.9943). (Found: C, 54.15; H, 3.60. Calc. for $\mathrm{C}_{10} \mathrm{H}_{8} \mathrm{FeF}_{2}$ : C, 54.08; $\left.\mathrm{H}, 3.63 \%\right)$.

\section{ASSOCIATED CONTENT}

\section{Supporting Information}

Experimental details, NMR, UV-vis and IR spectra, additional electrochemical and crystallographic information. This material is available free of charge via the Internet at http://pubs.acs.org.

\section{AUTHOR INFORMATION}

${ }^{\dagger}$ These authors contributed equally to this work.

\section{Corresponding Author}

* E-mail for T.A.: t.albrecht@imperial.ac.uk.

* E-mail for N.J.L.: n.long@imperial.ac.uk.

Notes

The authors declare no competing financial interest.

\section{ACKNOWLEDGMENT}

The authors thank Dr Ian Butler (Bangor University, UK) for useful discussions. S.D. thanks the China Scholarship Council and M.S.I., T.A. and N.J.L thank the Leverhulme Trust (RPG 2012-754) for funding. $\mathrm{MH}$ and $\mathrm{NMH}$ would like to acknowledge the use of the EPSRC UK National Service for Computational Chemistry Software (NSCCS) at Imperial College London in carrying out this work.

\section{REFERENCES}

1. (a) Kealy, T. J.; Pauson, P. L. Nature 1951, 168, 1039; (b) Nesmeyanov, A. N.; Perevalova, E. G.; Nesmeyanova, O. A. Dokl. Akad. Nauk SSSR 1955, 100, 1099; (c) Nesmeyanov, A. N.; Sazonova, V. A.; Drozd, V. N. Dokl. Akad. Nauk SSSR 1959, 126, 1004; (d) Hedberg, F. L.; Rosenberg, H. J. Organomet. Chem. 1971, 28, C14.

2. (a) Atkinson, R. C. J.; Gibson, V. C.; Long, N. J. Chem. Soc. Rev. 2004, 33, 313; (b) Butler, I. R. Eur. J. Inorg. Chem. 2012, 2012, 4387.

3. (a) Morisaki, Y.; Chujo, Y. Macromolecules 2003, 36, 9319; (b) Xue, W.-M.; Kühn, Fritz E.; Herdtweck, E.; Li, Q. Eur. J. Inorg. Chem. 2001, 2001, 213; (c) Sanechika, K.; Yamamoto, T.; Yamamoto, A. Polym. J. 1981, 13, 255.

4. (a) Engtrakul, C.; Sita, L. R. Nano Lett. 2001, 1, 541; (b) Chawdhury, N.; Long, N. J.; Mahon, M. F.; Ooi, L.-1.; Raithby, P. R.; Rooke, S.; White, A. J. P.; Williams, D. J.; Younus, M. J. Organomet. Chem. 2004, 689, 840; (c) Vollmann, M.; Butenschon, H. C. R. Chim. 2005, 8, 1282;9 (d) Getty, S. A.; Engtrakul, C.; Wang, L.; Liu, R.; Ke, S.-H.; 
Baranger, H. U.; Yang, W.; Fuhrer, M. S.; Sita, L. R. Phys. Rev. B 2005, 71, 241401; (e) Klein, A.; Lavastre, O.; Fiedler, J. Organometallics 2006, 25, 635; (f) Ma, J.; Vollmann, M.; Menzel, H.; Pohle, S.; Butenschön, H. J. Inorg. Organomet. Polym. Mater. 2008, 18, 41; (g) Engtrakul, C.; Sita, L. R. Organometallics 2008, 27, 927; (h) Fan, Y.; Liu, I. P.-C.; Fanwick, P. E.; Ren, T. Organometallics 2009, 28, 3959; (i) Baumgardt, I.; Butenschön, H. Eur. J. Inorg. Chem. 2010, 2010, 1076; (j) Lu, Q.; Wang, X.-H.; Wang, F.-S. Chin. J. Appl. Chem. 2011, 28, 136; (k) Inkpen, M. S.; Albrecht, T.; Long, N. J. Organometallics 2013, 32, 6053; (1) Inkpen, M. S.; White, A. J. P.; Albrecht, T.; Long, N. J. Dalton Trans. 2014, 43, 15287.

5. (a) Kovar, R. F.; Rausch, M. D.; Rosenberg, H. Organomet. Chem. Synth. 1971, 1, 173; (b) Gren, C. K., Vanderbilt University, 2009; (c)

6. Sünkel, K.; Weigand, S.; Hoffmann, A.; Blomeyer, S.; Reuter, C. G.; Vishnevskiy, Y. V.; Mitzel, N. W. J. Am. Chem. Soc. 2014, 137, 126.

7. (a) Peet, J. H. J.; Rockett, B. W. J. Organomet. Chem. 1974, 82, C57; (b) Adcock, W.; Khor, T. C. J. Organomet. Chem. 1975, 91, C20.

8. Popov, V. I.; Lib, M.; Haas, A. Ukr. Khim. Zh. (Russ. Ed.) $1990,56,1115$.

9. Sünkel, K.; Weigand, S. Inorg. Chim. Acta 2011, 370, 224.

10. (a) Curnow, O. J.; Hughes, R. P. J. Am. Chem. Soc. 1992, 114, 5895; (b) Hughes, R. P.; Zheng, X.; Ostrander, R. L.; Rheingold, A. L. Organometallics 1994, 13, 1567; (c) Hughes, R. P.; Zheng, X.; Morse, C. A.; Curnow, O. J.; Lomprey, J. R.; Rheingold, A. L.; Yap, G. P. A. Organometallics 1998, 17, 457.

11. (a) Winter, C. H. Synthesis and Properties of Perfluoroferrocene and Perfluororuthenocene. A Potential Class of High Temperature Materials., Dept. Chem., Wayne State Univ., Detroit, MI, USA., 1995; (b) Hedberg, F. L.; Rosenberg, H. J. Am. Chem. Soc. 1973, 95, 870.

12. Koplitz, L. V.; McClure, D. S.; Crerar, D. A. Inorg. Chem. 1987, 26, 308.

13. (a) Hedberg, F. L.; Rosenberg, H. Oxidation-resistant metallocenes. The synthesis and properties of perchloroferrocene and related polychlorinated and fluorinated ferrocenes, Air Force Materials Laboratory, Wright-Patterson Air Force Base, Ohio, 1970; (b) Hedberg, F. L.; Rosenberg, H. J. Am. Chem. Soc. 1970, 92, 3239.

14. (a) Cunningham, K. L.; McMillin, D. R. Polyhedron 1996, 15, 1673; (b) Goeltz, J. C.; Kubiak, C. P. Organometallics 2011, 30, 3908; (c) Inkpen, M. S.; Du, S.; Driver, M.; Albrecht, T.; Long, N. J. Dalton Trans. 2013, 42, 2813.

15. Bulfield, D.; Maschke, M.; Lieb, M.; Metzler-Nolte, N. J. Organomet. Chem. 2015, 797, 125.

16. Sanders, R.; Mueller-Westerhoff, U. T. J. Organomet. Chem. 1996, 512, 219.

17. (a) Rausch, M. D.; Ciappenelli, D. J. J. Organomet. Chem. 1967, 10, 127; (b) Bishop, J. J.; Davison, A.; Katcher, M. L.; Lichtenberg, D. W.; Merrill, R. E.; Smart, J. C. J. Organomet. Chem. 1971, 27, 241; (c) Butler, I. R.; Cullen, W. R.; Ni, J.; Rettig, S. J. Organometallics 1985, 4, 2196.

18. Bernhartzeder, S.; Sünkel, K. J. Organomet. Chem. 2012, $716,146$.

19. (a) Davis, F. A.; Han, W.; Murphy, C. K. J. Org. Chem. 1995, 60, 4730; (b) Snieckus, V.; Beaulieu, F.; Mohri, K.; Han, W.; Murphy, C. K.; Davis, F. A. Tetrahedron Lett. 1994, 35, 3465; (c) Umemoto, T.; Fukami, S.; Tomizawa, G.; Harasawa, K.; Kawada, K.; Tomita, K. J. Am. Chem. Soc. 1990, 112, 8563; (d) Yamada, S.; Knochel, P. Synthesis 2010, 2010, 2490; (e) Yamada, S.; Gavryushin, A.; Knochel, P. Angew. Chem., Int. Ed. 2010, 49, 2215.

20. Shechter, H.; Helling, J. F. J. Org. Chem. 1961, 26, 1034.
21. U.S.A. Pat, U.S. Patent 3,422,129 A, 1969.

22. Tang, P.; Wang, W.; Ritter, T. J. Am. Chem. Soc. 2011, 133, 11482.

23. Watson, D. A.; Su, M.; Teverovskiy, G.; Zhang, Y.; GarcíaFortanet, J.; Kinzel, T.; Buchwald, S. L. Science 2009, 325, 1661.

24. (a) Furuya, T.; Strom, A. E.; Ritter, T. J. Am. Chem. Soc. 2009, 131, 1662; (b) Tang, P.; Furuya, T.; Ritter, T. J. Am. Chem. Soc. 2010, 132, 12150.

25. (a) Furuya, T.; Kaiser, H. M.; Ritter, T. Angew. Chem., Int. Ed. 2008, 47, 5993; (b) Furuya, T.; Ritter, T. Org. Lett. 2009, $11,2860$.

26. Tang, P.; Ritter, T. Tetrahedron 2011, 67, 4449.

27. Fier, P. S.; Hartwig, J. F. J. Am. Chem. Soc. 2012, 134, 10795.

28. Furuya, T.; Kamlet, A. S.; Ritter, T. Nature 2011, 473, 470.

29. (a) Haaland, A. Acc. Chem. Res. 1979, 12, 415; (b) Long, N. J. Metallocenes: Introduction to Sandwich Complexes; WileyBlackwell, 1997.

30. (a) Pauling, L. The Nature of the Chemical Bond; 3rd ed.; Cornell University Press, 1960; (b) CRC Handbook of Chemistry and Physics; 95th ed.; CRC Press: United States, 2014-2015.

31. Allen, L. C. J. Am. Chem. Soc. 1989, 111, 9003.

32. Roemer, M.; Heinrich, D.; Kang, Y. K.; Chung, Y. K.; Lentz, D. Organometallics 2012, 31, 1500.

33. Brown, K. N.; Gulyas, P. T.; Lay, P. A.; McAlpine, N. S.; Masters, A. F.; Phillips, L. J. Chem. Soc., Dalton Trans. 1993, 835.

34. (a) Kelly, M. J.; Tirfoin, R.; Gilbert, J.; Aldridge, S. J. Organomet. Chem. 2014, 769, 11; (b) Ashley, A. E.; Herrington, T. J.; Wildgoose, G. G.; Zaher, H.; Thompson, A L.; Rees, N. H.; Krämer, T.; O'Hare, D. J. Am. Chem. Soc. 2011, 133, 14727.

35. Richardson, D. E.; Ryan, M. F.; Geiger, W. E.; Chin, T. T.; Hughes, R. P.; Curnow, O. J. Organometallics 1993, 12, 613.

36. (a) Hammett, L. P. Chem. Rev. 1935, 17, 125; (b) Hammett, L. P. J. Am. Chem. Soc. 1937, 59, 96.

37. Hansch, C.; Leo, A.; Taft, R. W. Chem. Rev. 1991, 91, 165.

38. Dowben, P. A.; Driscoll, D. C.; Tate, R. S.; Boag, N. M. Organometallics 1988, 7, 305.

39. (a) Gray, H. B.; Sohn, Y. S.; Hendrickson, N. J. Am. Chem. Soc. 1971, 93, 3603; (b) Rösch, N.; Johnson, K. H. Chem. Phys. Lett. 1974, 24, 179; (c) Yamaguchi, Y.; Ding, W.; Sanderson, C. T.; Borden, M. L.; Morgan, M. J.; Kutal, C. Coord. Chem. Rev. 2007, 251, 515.

40. Gardner, A. M.; Wright, T. G. J. Chem. Phys. 2011, 135, 114305.

41. Pickett, T. E.; Richards, C. J. Tetrahedron Lett. 1999, 40, 5251.

42. Roemer, M.; Nijhuis, C. A. Dalton Trans. 2014, 43, 11815.

43. Seiler, P.; Dunitz, J. D. Acta Crystallogr. Section B 1982, 38, 1741.

44. Romanov, A. S.; Mulroy, J. M.; Khrustalev, V. N.; Antipin, M. Y.; Timofeeva, T. V. Acta Crystallogr., Sect. C: Cryst. Struct. Commun. 2009, 65, m426.

45. Laus, G.; Wurst, K.; Stolz, W.; Schottenberger, H. Z. Kristallogr. - New Cryst. Struct. 2005, 220, 239.

46. Hnetinka, C. A.; Hunter, A. D.; Zeller, M.; Lesley, M. J. G. Acta Crystallogr., Sect. E: Struct. Rep. Online 2004, 60, m1806.

47. Weigend, F.; Ahlrichs, R. Phys. Chem. Chem. Phys. 2005, 7, 3297.

48. Grimme, S. J. Comput. Chem. 2006, 27, 1787.

49. Oshima, M.; Murao, T.; Sakurai, Y. Academic Reports Fac. Eng. Tokyo, Poytech. Univ. 2007, 30, 56.59.

50. Eckert, F.; Leito, I.; Kaljurand, I.; Kutt, A.; Klamt, A.; Diedenhofen, M. J. Comput. Chem. 2009, 30, 799. 
51. (a) Boev, V. I.; Dombrovskii, A. V. Izv. Vyssh. Uchebn. Zaved., Khim. Khim. T. 1977, 20, 1789; (b) Han, Y.-H.; Heeg, M. J.; Winter, C. H. Organometallics 1994, 13, 3009.

52. Khobragade, D. A.; Mahamulkar, S. G.; Pospíšil, L.; Císařová, I.; Rulíšek, L.; Jahn, U. Chem. Eur. J. 2012, 18, 12267. 